\title{
The Impact of Marketing Mix (4Ps) on Warehousing Operations: Case Study of Unilever Nigeria PLC
}

\author{
Geraldine Okeudo ${ }^{* 1}$ and Okoli, Margaret. $\mathrm{N}^{2}$ \\ ${ }^{I}$ Department of Transport Management Technology, Federal University of Technology, Owerri. Imo State, Nigeria \\ ${ }^{2}$ Department of Financial Management Technology, Federal University of Technology, Owerri. Imo State, Nigeria
}

\begin{abstract}
The study investigates the impact of marketing mix (4ps) on warehousing operations with a case study of Unilever Nigeria Plc. with objectives to aim at establishing a link between the resultant effects of marketing mix efforts on warehousing operations to find challenges and opportunities to improve on. Data used where secondary data collected from the warehouse activity profiles. Through-put/hour is used the estimated the activity at the warehouse; Sales in volumes is used the estimated the sales level. Data was analysed the regression model to determine what influence that marketing mix elements has on warehouse activity levels. Findings show that the higher sales go the higher the activities that constitute warehousing operations in the warehouse and price and promotional activities has a low influence on this warehouse operations. Consequently, it was concluded that the price and promotion activities have low influence on the model while sales-in-volume has the highest influence on the model. The relationship shows that the higher the volume-in-sales the activity is the warehouse operations while price and promotion activities do not have consider impact on these activities. We therefore recommend that Companies should develop better internal information system so as to effectively convey the information on real time basis within the firm especially when these warehouses are operated of decentralized policy.
\end{abstract}

Keywords: Marketing mix, warehousing operations, product, price, place and promotion

\section{Introduction}

Many marketing firms in Africa are faced with increasing cost of production, poor transport system and highly instable market conditions. Many these firms use warehouse or distribution centres to mitigate the impact of these uncertainties in the operation of their business. These warehouses are either public, privately or 3-party owned but they all serve the one major purpose to smoothen the forces of demand and supply and to the firms products closer to the domestic markets. Ironically, many marketing firms are very unstable with their activities which are characterized by frequently changing prices, unproductive promotional schemes, poor quality of products and uneven distribution and availability of products among domestic markets. The aforementioned paragraph forms the basis for this study on establishing a link between the resultant effects of marketing mix efforts on warehousing operations, find challenges and opportunities to improve on.

Contemporary corporations have restructured their distribution systems to take benefit from the major

${ }^{*}$ Corresponding author improvements that were made in the information system, transportation and storage infrastructure. The introduction of Information Management System (IMS) has greatly eased order receipt; order processing, resource allocation, order invoicing and analysis of distribution cost which has promoted the application of operations research techniques in warehousing operations.

\section{Profile of Unilever Nigeria PLC}

Unilever Nigeria PLC is one of Nigeria's largest consumer goods companies with coverage network that spans across all the states in the nation and a distribution centre in almost every town and city in the country. The company's long-term success of the business stems from the strong relationship with the consumer based on the deep roots in the local cultures and markets, creating products that help them to feel good, look good and get more out of life and the total commitment to exceptional standards of performance and productivity (Paul, 2008).

According to Unilever Nigeria report in 2005. Unilever Nigeria Plc. operates in Nigeria with one production plant located at Oregun, Lagos state. The company produces its products and manages the 
complex logistics framework through third-party logistics (3PL) companies which provide support in sales and warehousing, distribution and merchandising. Unilever South-East has a sales potential of over 20,000 existing and potential retail outlets with 21 distribution centres. South-eastern Nigeria has proved to be a potential new market focus for the company with growth in major cities in the region like Onitsha, Warri, Aba, Enugu, Port Harcourt and Calabar. The company has faced setback with meeting up to the full potential of the market size but has been constrained by lack of logistics planning and financial constraints at redistribution level (Unilever Report 2005).

\section{Concept of 4 P'S}

Much of the original philosophy about the marketing mix emerged from the work of McCarthy (1960), who saw the four principal elements of marketing mix to be the Product, Price, Promotion and Place (Distribution). Subsequently, the marketing mix has been developed to include the three 'softer' elements of People, Physical evidence and Process management. Thomas (1987, p. 238) has highlighted, that product offered by a company will ultimately determine the nature of the business and the marketplace perception of the business. The principal concern of most organizations is usually product strategy and management rather than market strategy and management. Therefore, market strategy for a product is formulated around one or more marketing mix variables which impose strain on the warehousing system that holds such goods.

\section{Warehousing}

Warehousing can help firms manage goods and space more effectively, reduce costs and waste, and gain control over warehouse operations. With access to real-time information, accurate inventory data, warehouse professionals save time by allocating items or performing physical inventories, sales representatives can keep track on stock availability, and buyers can maintain optimum stock levels while minimizing transport costs. The warehouse is the origin of every physical distribution network in physical distribution management and system. It acts as a distribution hub for products like those found in other transport systems (McCarthy, 1960). Warehousing is costly in terms of human resources and the facilities and equipment required, and its performance will affect directly on overall supply chain performance. Inadequate design or managing of warehouse systems will jeopardize the achievement of required customer service levels and the maintenance of stock integrity, and result in unnecessarily high costs (Mohan, 2012).

\section{Marketing mix defined}

Once the company has decided on its overall competitive marketing strategy, it is ready to begin planning the details of the marketing mix. The marketing mix is the set of controllable marketing variables that the firm blends to produce the response it wants in the target market. The marketing mix consists of everything that the firm can do to influence the demand for its product. These variables are often referred to as the "four Ps" (product, price, place, promotion) (Richard, \& Colin, 2003).

\section{Product}

Product is a combination of a firm's resources in form a single unit offered to a customer so as to make profit. The choices that are made concerning the product can be: brand name, design, functionality, protection, maintenance, packaging, guarantee, accessories and services. To define what the product is supposed to represent questions may be asked like: What does the consumer want from the product? What requirements does it satisfy? What characteristics is it supposed to have to meet customers' requirements? How is it different from the one product of your competitors? (Richard, \& Colin, 2003).

\section{Price}

Price: refers to the choice of appropriate approaches to forming the actual price of the product. Each customer tries to weights benefits of product against its cost in order to make a purchase. It is also important to mention that while all the other three aspects of marketing mix are costs, price is the only one which creates sales revenue. The questions to be asked in order to understand the pricing element better are: What is the value of the product or service to the purchaser? Is the costumer price sensitive? How will your price be different with that of your competitors? Richard, \& Colin, 2003).

\section{Place}

Place; element of the marketing mix is the one being concerned with a range of methods of transporting and storing goods, and then making them available to the consumers in the most continent way. Delivering the right product to the proper place at the right time requires designing of a distribution system. When referring to 'place' marketer has to make decision on 
distribution channels and centres, transportation, warehousing, order processing, etc.

These questions are usually asked; where do buyers search for your product? In what kind of stored do they look for the product? How can you contact the appropriate distribution channels? (Richard, \& Colin, 2003).

\section{Promotion}

Promotion is concerned with presenting customers with information needed to make a decision. The fact is that, even though being sometimes extremely costly, promotion can increase the sales significantly. These are the questions that can be helpful when defining this particular element of marketing mix: Where and when can one get across your marketing messages to the target market? When is the best time to promote? Is there seasonality in the market?( Richard, \& Colin, 2003).

\section{Influence of marketing mix on Warehousing}

The significance of establishing a relationship between marketing mix and warehousing are due to the following reasons. Companies of today are placing greater emphasis on warehousing (physical distribution) for several reasons:

First, customer service and satisfaction have become the cornerstones of marketing mix strategy and distribution as an important customer service element i.e. companies are finding that they can draw and keep customers by providing better service at relatively lower prices through better physical distribution system.

Secondly, the escalating growth of product brands and lines in recent times, has created a need for improved logistics operations especially on the warehouse that holds the products and perform tasks like order receipt and filling across a heterogeneous choice of products requested by the customers.

Thirdly, about $20 \%$ of an average product's price is accounted for by shipping and transport alone. Poor physical distribution decisions results in high costs. Improvements in physical distribution and warehousing efficiency can yield tremendous cost savings for both the company and its customers.

Finally, improvements in information technology (ITS) have created opportunities for major gains in distribution efficiency. With IT applications that help firms to track their operations i.e. giving them a better picture of the effect of their operations in the marketplace.

Place the platform on which all the other elements operate. Of what use is a promotion or price strategy or product ergonomic features if the products are not readily available. Warehousing being part of place element has considerable influence on the success of the marketing mix strategies (Philip, 1991).

\section{Methodology}

The research is aimed at analyzing the relationship between changes in elements of the marketing mix and the warehousing activity levels. Omo being one the most active products of Unilever Nigeria, which has close substitutes like Sunlight and major competitive products like Areil and Klin was chosen as the focus of the research. The length of the research was from the first 25 weeks of the year, covering the months of January to June. This period covers peak periods of high market activity during restocking periods of late January and February and celebrations like Easter. The extended period was necessary so as to develop a trending all the variables to be discussed.

The majority type of data used where secondary data collected from the warehouse activity profiles. Through-put/hour is used the estimated the activity at the warehouse; Sales in volumes is used the estimated the sales level, price were gotten from the price list and the promotion activity index was developed from various indictors of promotion levels.

\section{Data Analysis and Interpretationa}

Regression model was used to determine what influence that marketing mix elements has on warehouse activity levels. Meanwhile graph with forecast trend lines were used to give a more pictorial view of the nature of the relationship.

$$
Y=a+b_{1} X_{1}+b_{2} X_{2}+b_{n} X_{n}+e_{i}
$$

Using Microsoft excel and Mega stat add-in to analyse these data gotten related records at the warehouse. Below are the results of the analysis conducted of the data. 
Table 1. The regression and ANOVA analysis output.

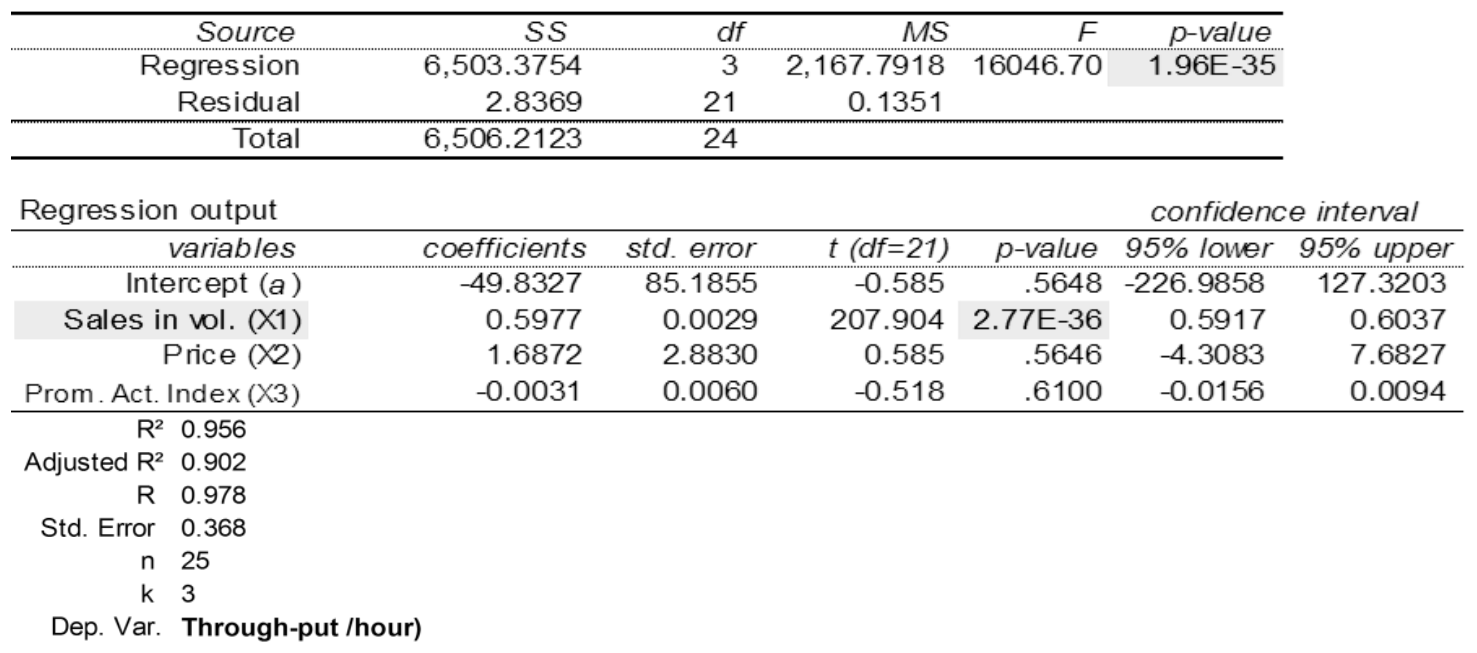

The table shows that the independent variable has a strong influence on both the regression model $\left(R^{2}=0.956\right)$ and the dependent variable $\left(\operatorname{Adj} . R^{2}=\right.$ $0.902)$. The analysis returns a positive confirmation to our accretion that marketing mix has influence on warehouse operations. The ANOVA table shows that a combination of these variables is significant to regression model. The resultant regression model calculated is:
$Y=-49.83+0.59 X_{1}+1.69 X_{2}-0.0031 X_{3}$

The price and promotion activities have low influence on the model while sales-in-volume has the highest influence on the model. The relationship shows that the higher the volume-in-sales the activity is the warehouse operations while price and promotion activities do not have consider impact on these activates.

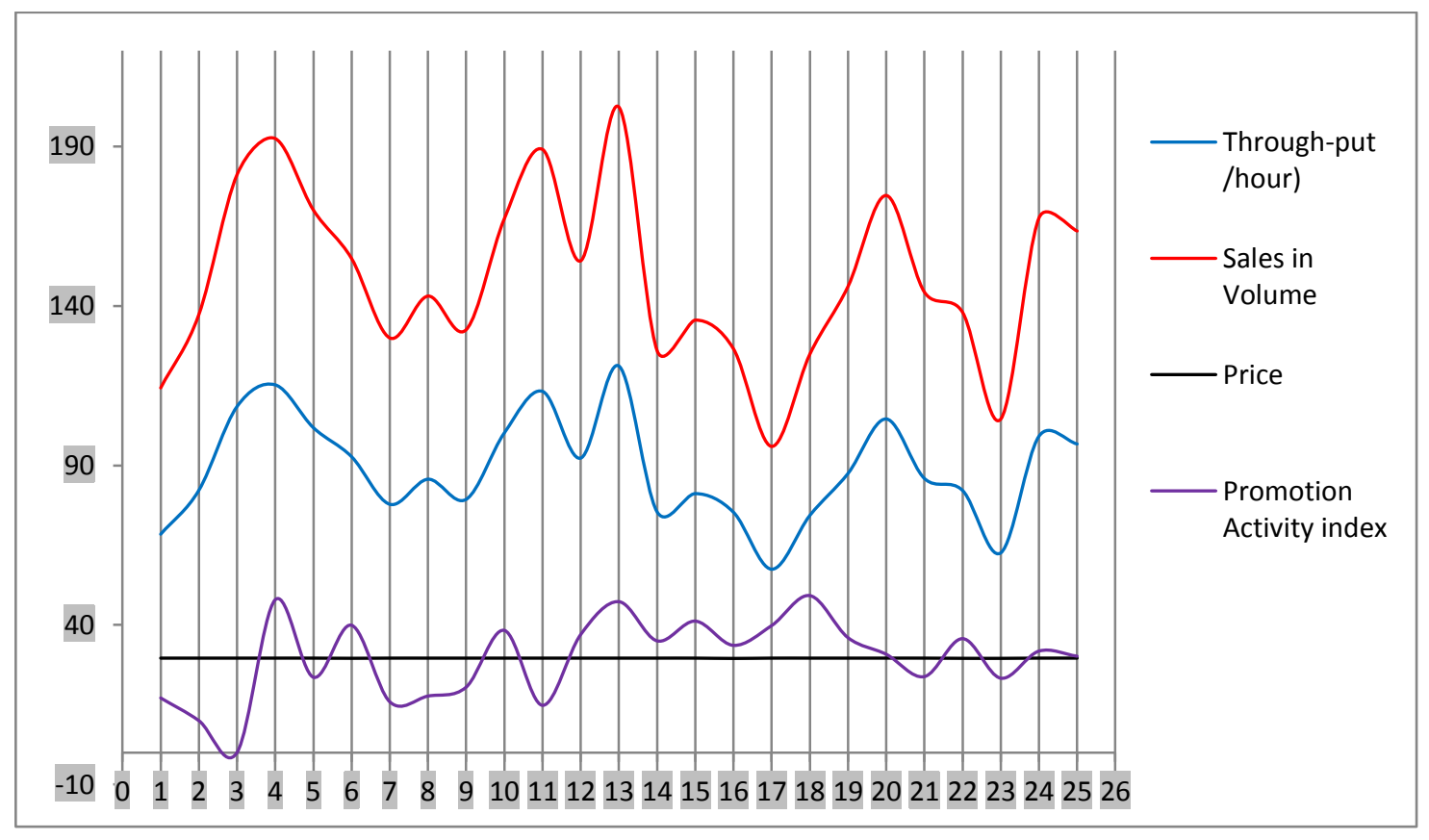

Figure 1. Graphical presentation of relationship between the variables. 
The above graph shows that there a similarities between the trends in through-put/hour and sales-involume. Price which is relatively stable throughout the period of study has no trend similarities with any of the other variables but to some extent promotional activities has trend similarities with through-put/hour and sales-in-volume.

\section{Findings}

The findings show that the higher sales go the higher the activities that constitute warehousing operations in the warehouse and price and promotional activities has a low influence on this warehouse operations. Though most warehouses do not advertise rather they concentrate on redistribution and product assortment, yet they have to advertise in there locality since better understand their customers.

Price from the suppliers is very stable compare to what we see in the market place. This shows that most of the prices changes come through the middle men (wholesaler, retailer) closer the final costumer. Transport has been major cost factor that accorded for such instability in prices as most warehouse bear the transportation cost of both receiving the stock and redistributing them to final consumers.

\section{Conclusion}

The price and promotion activities have low influence on the model while sales-in-volume has the highest influence on the model. The relationship shows that the higher the volume-in-sales the activity is the warehouse operations while price and promotion activities do not have consider impact on these activities.

\section{Recommendations}

Companies should develop better internal information system so as to effectively convey the information on real time basis within the firm especially when these warehouses are operated of decentralized policy. In achieving the companies has to invest into IT assistance in convey information of the physical stock position of the warehouse so enable the maximise sales opportunity during promotion and price changes. If the warehouses are operated on decentralized policy the company should have representative to ensure proper feedback of warehouse operations are properly report for necessary actions to be taken. Since warehouse is major player in the place utility of the marketing mix. Marketers and producer has to pay attention to how products are handled in these warehouses and what distribute is most for the target market. Change in products attributes and introduction of new products as a considerable impact on warehousing activities though this could not be accounted for the course of the research. The most straining is the continuous extension of product lines by manufactures and constant change in packaging. The warehouse should choose the target market and provide the right product mix of their customers. The warehouses should contribute in packaging decisions through feedback from their customers.

\section{References}

Ahmed, D. M. (n.d.). MGT301 principles of marketing. Virtual University ( $\mathrm{Vu}$ ) of Pakistan.

Adeagbo .P. (2011). Sales management and process., Better salesmen in Nigeria : An overview, 13 slides. Lagos Business Summit. November 2013.

MCarthy. O. (1960). Warehouse operations and optimization. British Journal of Science. shefield. Concord Press International, 4(3),245-278.

Mohan, P. (2012). Cost effectiveness in warehouse Operations; Strategic Marketing and management. Oxford: Elsevier Butterworth-Heinemann.

Thomas. B.A. (1987) . Logistics cost reduction: A solution to firm revenue, British Journal of Science. Sheffield. Concord Press International, 3(1),238-248.

Philip,K.(1991). Marketing management: Analysis, planning, implementation, and control" 7th Edition, Englewood Cliffs, NJ: Prentice-Hall.

Paul ,P. (2009): Conversations on global business trends. quaterly report on business, Ontario.Oct,2009.

Richard, W., \& Colin, G. (2003). Strategic marketing and management. Oxford: Elsevier Butterworth-Heinemann.

Unilever Nigeria.(2005). CEF Module 1 Roles \& Responsibility. TDOM,Workshop(Manila), 13 slides 